\title{
The Role of Menopausal Hormone Therapy and Serms in the Long-Term Treatment of Osteoporosis
}

\author{
Erik Fink Eriksen* \\ Spesialistsenteret Pilestredet Park and University of Oslo, Oslo, Norway \\ ${ }^{*}$ Corresponding author: Erik Fink Eriksen, Spesialistsenteret Pilestredet Park and University of Oslo, Oslo, Norway
}

Received: April 18, 2021; Accepted: April 28, 2021; Published: May 07, 2021

\section{Introduction}

Osteoporosis remains an under prioritized and undertreated disease, despite the emergence of very effective and safe treatment modalities over the last 30 years. Prior to this development Hormone Replacement Therapy (HRT), be it as estrogen only (ET) or combined with a progestogen (HT) in hysterectomized or women with intact uterus, respectively, were the main treatment options. Commonly used doses are 0,5-2 mg/day (oral $17 \beta$ estradiol), 0,3-1,25 mg/ day (Conjugated estrogens) and 25-100 ug/24 h (transdermal administration).

After the initial publications of the Women's Health Initiative (WHI) trial 2002 [1], HRT has fallen out of favor as a treatment modality for osteoporosis. It is not recommended for this purpose in most countries, and the US Preventive Task Force (USPTF) advices against its use for long term treatment. Selective Estrogen Receptor Modulators (SERMs) were subsequently developed in an attempt to develop drugs, which reduced CV and breast cancer risk, while still reducing risk of osteoporotic fracture. The majority of SERMS under development, however, never made it to market. Arzoxifene, droloxifene, idoxifene, lasofoxifene, levormeloxifene are names associated with very expensive development programs, never resulting in a marketable compound due to either lack of efficacy or more often safety signals. Thus, only Raloxifene and Basedoxifene are available for osteoporosis treatment, and the latter is mainly used in combination with Premarin as a treatment for menopausal symptoms [2]. The use of SERMS in osteoporosis treatment has been limited by the absence of efficacy against non-vertebral fractures. Only one SERM (lasofoxifene) demonstrated significant reduction of nonvertebral fractures, but was not approved for clinical use.

In this short review. I will try to summarize the pertinent information pertaining to the use of HRT, or Menopausal Hormone Therapy (MHT) as it is more appropriately called now, and SERMS in the treatment of osteoporosis. In certain countries tibolone $(1,25-$ $2,5 \mathrm{mg} /$ day) is an option. It is a compound, which binds to all 3 sexhormone receptors. In younger postmenopausal women it preserves bone mass and increases sexual wellbeing and libido. Its use in older women is not recommended, however, after a 2 -fold increase in stroke risk was seen, and caused discontinuation of the large scale LIFT study (4538 women aged 60-85) in 2006 [3]. I will therefore not consider
Tibolone as an option for long term treatment of osteoporosis in the following.

\section{Effects of Hormone Replacement Therapy (HRT, MHT) on Bone}

Hormone replacement therapy (menopausal hormone therapy denotes the use of estrogen either alone or in combination with a progestogen to alleviate menopausal symptoms. Estrogen monotherapy can only be given to women, who have undergone hysterectomy. Estrogen has to be combined with a progestogen in non-hysterectomized women, in order to avoid excessive endometrial proliferation, which may cause menstrual bleedings and increased risk of endometrial cancer.

\section{Mechanism of Action}

Estrogen has specific effects on bone remodeling promoted mainly via binding to the Estrogen Receptor a (ER $\alpha)$ demonstrated in both osteoblasts, osteocytes and osteoclasts [4,5]. Binding of 17 - $\beta$-estradiol to ERa in osteoblasts and osteocytes results in reduced levels of the central regulator of osteoclast differentiation Rank Ligand (RANKL) and increased levels of the endogenous inhibitor of RANKL, Osteoprotegerin (OPG). Other estrogen effects are reduced levels of osteoclast stimulating proinflammatory cytokines resulting in lower osteoclast numbers and reduced remodeling activity [6]. Estrogen exerts positive effects on osteocytes and osteoblasts by preserving mechano-sensing osteocytes in bone and increasing osteoblast life span and activity [6]. At the tissue level these effects result in lowering of bone turnover by $50-70 \%$ and preservation of the balance between resorption and bone formation [7]. Khastgir et al., corroborated these results and demonstrated a significant increase in trabecular bone structural units (wall thickness) pointing towards a possible osteoblast stimulatory, osteoanabolic, effect [8]. This is probably why estrogen supplementation after menopause reverses bone loss to a gain in bone mass over time. Such effects on tissue level bone balance have not been demonstrated for nitrogen containing bisphosphonates; the most widely used anti-osteoporotic agents.

SERMS bind to both estrogen receptors (ERaand ER $\beta$ ), and also exerts differential effects at estrogen receptor response elements in the nucleus $[9,10]$. The effects at the tissue level of are less than estrogen in terms of suppression of bone turnover and no data are 
available on bone balance [11]. This is probably the main reason for the limited antifracture efficacy of most SERMS showing significant reduction of vertebral fractures only in clinical trials, lasofoxifene being the exception with non-vertebral antifracture efficacy. Looking at combined results obtained with HRT, SERMS and bisphosphonates, it seems that bone turnover reduction has to exceed $50 \%$ in order to achieve reduction of non-vertebral fractures [11-13].

\section{Effects of MHT on Bone}

The positive effects of MHT on bone mineral density in postmenopausal women, who otherwise exhibit accelerated bone loss has been documented in numerous studies since the early studies of Lindsay et al. [14]. In early postmenopausal women Increases hover around $2 \%$ at the spine and $1 \%$ at the hip after 2 years [14-16]. Studies employing longer treatment periods report 6-9\% increases at the spine and $4-6 \%$ at the hip [17]. A single study analyzing BMD changes after 16 years of treatment with estrogen implants reported $20-25 \%$ increases in BMD [18]. The data also clearly show dose dependency [19], a feature which should be considered when contemplating dose reductions in older women as proposed in some guidelines. The WHI study provided the first evidence of significant antifracture efficacy in a randomized controlled study, with $34 \%$ reduction of hip and vertebral fractures and $23 \%$ reduction of other fractures [1]. These effects are mediated mainly via a reduction of bone turnover, equal to what is seen for other antiresorptive drugs like bisphosphonates and denosumab, but the effects on bone balance may also play a role. Based on bone markers the average reduction of bone turnover hovers around $50-70 \%$ [16], which is a reduction with demonstrable effects on non-vertebral fractures as shown in WHI. It is generally less than shown for bisphosphonates and denosumab, which achieve 70-80\% and $>90 \%$ reduction of bone turnover, respectively $[16,20,21]$.

\section{Long Term Effects of MHT on Bone}

As mentioned above the few long-term studies available suggest pronounced improvements in BMD at the order of $10-25 \%$ with treatment periods of 10-16 years. This is in keeping with my personal experience with BMD assessments in older women who continued MHT until the age of 70, who virtually all show values in the upper range of normal in spine and hip. Middelton and Steele [17] analyzed BMD prospectively in a reasonably large cohort of women on placebo, treated with HRT for 2 years. and HRT for 9 years. They found that just 2 years of treatment prevented the bone loss seen in the placebo group. Women treated for 9 years exhibited a continuous increase in BMD at both spine and hip ending up at levels 8 and 2, 6\% over baseline. Bagger et al. [22] analyzed fractures in women 5, 10 and 15 years after short term MHT (2-3 years) and found a persistent $40-60 \%$ reduction of all osteoporotic fractures 15 years later. Similar analyses of the WHI cohort also demonstrated preserved antifracture efficacy in women given CEE only 5 years after discontinuation. No such reduction was seen for the CEE+MPA group [23]. This continuous increase is of interest, because it points towards a continued improvement over time and is in keeping with the demonstration of improved bone formation and reduced bone resorption demonstrated in the histological studies outlined above (Figure 1).

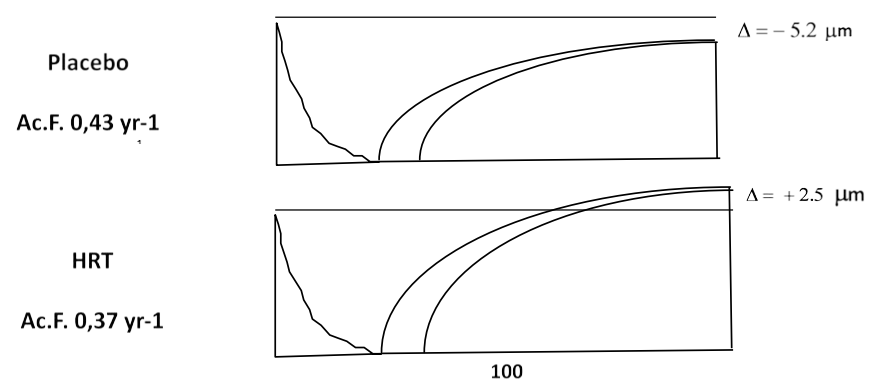

Figure 1: Reconstructed bone remodeling sequences in early postmenopausal women treated with MHT or placebo for 2 years. Bone resorption is shown on the left and the bone formation sequence on the right. One remodeling cycle lasts around 200 days. Note the development of a negative balance between resorption and formation in untreated women and the preservation of bone balance in women on MHT. Also note the reduction of the activation frequency (Ac.F), which is a histomorphometric measure of bone turnover. From Eriksen et al. J Bone Miner Res, 14(7), 1217-1221, with permission.

\section{Clinical Effects of SERMS on Bone}

SERMS (raloxifene, arzoxifene, lasofoxifene, basedoxifene) achieve less reduction of bone turnover hovering around $15-50 \%$ and in line with this lesser effect on bone turnover, BMD increases are also lower than those reported for MHT around 1-2,9\% after 2-3 years [24-27]. All 4 SERMS reduce vertebral fractures by $30 \%$ (raloxifene $60 \mathrm{mg}$ ), $41 \%$ (arzoxifene $20 \mathrm{mg}$ ), $42 \%$ (lasofoxifene $0,5 \mathrm{mg}$ ) and $42 \%$ (basedoxifene $20 \mathrm{mg}$ ). The effects on nonvertebral fractures were, how ever, only significant for lasofoxifene $0,5 \mathrm{mg}$ (RRR $24 \%$; $\mathrm{p}=0,02$ ), Basedoxifene reported significant reduction (50\%) of nonvertebral fractures was demonstrable in a post hoc high-risk group $(p=0,02)$ (Figure 2).

\section{Safety}

\section{MHT}

The initial conclusions from the WHI study emphasized an unfavorable risk/benefit ratio, mainly focusing on an increased risk of breast cancer, stroke and thromboembolism. The reduced risk of colon cancer, diabetes and reduced cancer and all-cause mortality also emerging from WHI [1], are rarely mentioned.

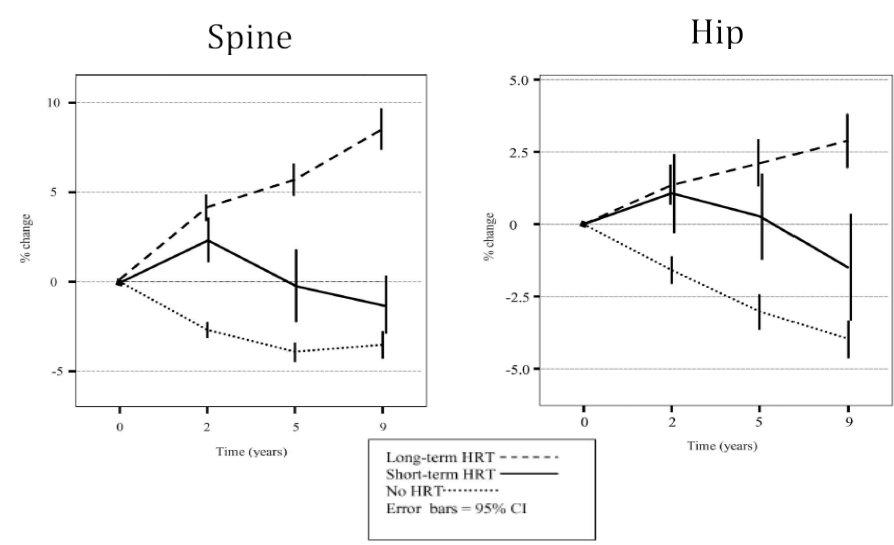

Figure 2: BMD over time in women treated with MHT for 2 years (short term HRT) and 9 years (long term HRT), compared to untreated women (No HRT). From Middleton ET \& Steel SA Climacteric 2007; 10:257-263 with permission. 
Later studies showed that the increased risk of breast cancer was mainly attributable to the progestogen component administered with estrogen to women with an intact uterus, as hysterectomized women given estrogen only did not display increased risk [28,29]. Moreover, the statistical analysis of the breast cancer risk in WHI has been called into question [28]. Finally, the discrepancy between WHI data and e.g. the DOPS data with respect to breast cancer risk (see below) may be partly due to estrogens used (13 different estrogen compounds in CEE used in WHI vs. $17 \beta$-estradiol used in DOPS) as well as a much different age profile.

The increased CV risk also depends on the woman's age at initiation of therapy, with women below the age of 60 when starting MHT actually exhibiting protection against CV events, the so called "timing hypothesis" [29-31]. This notion is supported by a recent Cochrane analysis. It found that those who started hormone therapy less than 10 years after menopause exhibited $30 \%$ lower mortality and $48 \%$ reduction of coronary heart disease. The risk of venous thromboembolism was still increased by a factor 1,7 in estrogen treated subjects, but no detectable increase in stroke risk was demonstrable. Also worth noting, was the finding, that MHT initiation more than 10 years after menopause had little effect on risk of death or coronary heart disease, while risk of stroke and DVT were still increased by a factor 1,2 and 2,0 respectively. The findings of this Cochrane analysis are also of interest in light of the results obtained in the Danish DOPS study. In this study 1000 women, all below the age of 60, were randomized to either placebo of oral MHT. After 10 years, the study was stopped due to the findings of the WHI study, but women staying on HRT and placebo were still followed via health registers. After 10 years women on HRT showed a 52\% lower risk of $\mathrm{CV}$ disease and $\mathrm{CV}$ death, and this risk reduction was preserved over 18 years in women staying on MHT. Breast cancer risk in hormone users was not increased in this study. Risk of thromboembolism was not increased significantly. The reanalysis of the mortality date emerging from WHI by Manson et al. [29] revealed that the Hazard ratio for allcause mortality was 0.61 (95\% CI, 0.43-0.87) during the intervention phase in WHI and 0.87 (95\% CI, 0.76-1.00) during the cumulative 18year follow-up after the trial.

Transdermal administration of estradiol has not been associated with increased risk of thromboembolism [32,33]. Micronized progesterone seems to reduce the risk of DVT, and has not been associated with increased breast cancer risk [33]. Medroxyprogesterone Acetate (MPA) has been associated with increased risk of both breast cancer and venous thrombosis.

\section{Serms}

Except for lasofoxifene, all SERMS have been associated with increased risk (RR 1,4-2,7) of venous thromboembolism [9,34-36]. This has to be weighed against significant reductions in risk of breast cancer (RR 0,19-0,44) demonstrated for raloxifene, arzoxifene and lasofoxifene [9,34-36]. Raloxifene increased risk of fatal stroke by $44 \%$ [37], but this has not been with other SERMS. Lasofoxifene has the ideal profile of a SERM. At a dose of $0.5 \mathrm{mg}$ per day it reduced risks of nonvertebral and vertebral fractures, ER-positive breast cancer, coronary heart disease, but further development was stopped due to increased mortality in subjects treated with the lower dose of $0,25 \mathrm{mg}$ [34].

\section{Conclusions}

The WHI data still form the basis for most safety considerations pertaining to MHT, and if you are a evidence based medicine purist, this will remain the case, until another well conducted similar sized randomized trial is published. However, with the price tag linked to such trials, this will probably not happen in the near future. We are therefore left with the sub-analyses emerging from WHI and other randomized trials like the Danish DOPS study, showing a much different safety profile. The interpretation depends on the relative weight one places on the different adverse effects, but to use WHI as the only basis for guidelines can certainly be discussed as emphasized by Langer et al. [28]. To me the long-term $\mathrm{CV}$ protection is crucial and outweighs other potential safety issues. Moreover, the thromboembolic risk seen with oral hormone administration seems to be absent with transdermal administration. The learning's from the trials available can therefore in my view be summarized as follows:

- MHT should be started in early menopause and not after the age of 60 .

- MHT should preferably be given by the transdermal route, as it reduces risk of thromboembolism.

- Micronized progesterone is preferable to progestogen, but if the latter is used systemic exposure should be minimized (e.g. administration via intrauterine device).

- If started before the age of $60, \mathrm{MHT}$ reduces CV risk by $50 \%$, and it can be continued beyond the age of 60 with continued $\mathrm{CV}$ protection.

- MHT is also associated with reduced risk of diabetes and colon cancer.

- The data on breast cancer risk associated with MHT are equivocal, and seem to depend on estrogen and progestogen used.

- MHT initiated before the age of 60 is associated with reduced all-cause mortality.

- It should not be forgotten, that MHT will also improve general quality of life for most women by reducing hot flushes, improving sleep and sex life by improving libido and vaginal dryness.

- MHT remains contraindicated in women with active or previous breast cancer. Also, women with hormone sensitive migraine also may encounter worsening of headaches.

In my view MHT therefore constitutes an effective and safe antiosteoporotic medication for younger women with low bone mass at menopause with additional positive effects on health:

- MHT reduces risks of both vertebral and non-vertebral fractures.

- $\quad$ MHT is associated with a long-term continuous increase in bone mass, resulting in values in the upper normal range of normal after 10-15 years in most long-term users. 
- Even short-term use of MHT prevents accelerated bone loss in early menopause, and improves bone status in the long run, despite postmenopausal bone loss rates ensuing after discontinuation.

- MHT has not been associated with very rare side effects like osteonecrosis of the jaw and atypical femoral fractures seen in long term users of bisphosphonates and denosumab.

- In women with prevalent fractures, I would still prefer bisphosphonates possibly in combination with MHT, and in more severe cases (multiple vertebral fractures, severe compression fractures ( $>40 \%$ compression, BMD T-score $<-4,0$ or treatment failure on antiresorptive therapy) osteoanabolic therapies like teriparatide or romosozumab are more effective.

The role of SERMS in the treatment of osteoporosis is in my view limited, due to the absence efficacy against non-vertebral fractures, which constitutes the vast majority of all clinical fracrtures. They remain, however, an option for women at high risk of breast cancer.

\section{References}

1. Rossouw JE, Anderson GL, Prentice RL, LaCroix AZ, Kooperberg C, et al. (2002) Risks and benefits of estrogen plus progestin in healthy postmenopausal women: principal results From the Women's Health Initiative randomized controlled trial. JAMA 288: 321-333. [crossref]

2. Mirkin S, Komm B, Pickar JH (2014) Conjugated estrogen/bazedoxifene tablets for the treatment of moderate-to-severe vasomotor symptoms associated with menopause. Womens Health (Lond) 10: 135-146. [crossref]

3. Cummings SR, Ettinger B, Delmas PD, Kenemans P, Stathopoulos V, et al. (2008) The effects of tibolone in older postmenopausal women. N Engl J Med 359: 697-708. [crossref]

4. Eriksen EF, Colvard DS, Berg NJ, Graham ML, Mann KG, et al. (1988) Evidence of estrogen receptors in normal human osteoblast-like cells. Science 241: 84-86. [crossref]

5. Oursler MJ, Landers JP, Riggs BL, Spelsberg TC (1993) Oestrogen effects on osteoblasts and osteoclasts. Ann Med 25: 361-371. [crossref]

6. Khosla S, Oursler MJ, Monroe DG (2012) Estrogen and the skeleton. Trends Endocrinol Metab 23: 576-581. [crossref]

7. Eriksen EF, Langdahl B, Vesterby A, Rungby J, Kassem M (1999) Hormone replacement therapy prevents osteoclastic hyperactivity: A histomorphometric study in early postmenopausal women. J Bone Miner Res 14: 1217-1221. [crossref]

8. Khastgir G, Studd J, Holland N, Alaghband-Zadeh J, Fox S, et al. (2001) Anabolic effect of estrogen replacement on bone in postmenopausal women with osteoporosis: histomorphometric evidence in a longitudinal study. J Clin Endocrinol Metab 86: 289295. [crossref]

9. Ettinger B, Black DM, Mitlak BH, Knickerbocker RK, Nickelsen T, et al. (1999) Reduction of vertebral fracture risk in postmenopausal women with osteoporosis treated with raloxifene: results from a 3-year randomized clinical trial. Multiple Outcomes of Raloxifene Evaluation (MORE) Investigators. JAMA 282: 637-645. [crossref]

10. Paech K, Webb P, Kuiper GG, Nilsson S, Gustafsson J, et al. (1997) Differential ligand activation of estrogen receptors ERalpha and ERbeta at AP1 sites. Science 277: 15081510. [crossref]

11. Weinstein RS, Parfitt AM, Marcus R, Greenwald M, Crans G, et al. (2003) Effects of raloxifene, hormone replacement therapy, and placebo on bone turnover in postmenopausal women. Osteoporos Int 14: 814-822. [crossref]

12. Bauer DC, Black DM, Garnero P, Hochberg M, Ott S, et al. (2004) Change in bone turnover and hip, non-spine, and vertebral fracture in alendronate-treated women: the fracture intervention trial. J Bone Miner Res 19: 1250-1258. [crossref]
13. Rogers A, Glover SJ, Eastell R (2009) A randomised, double-blinded, placebocontrolled, trial to determine the individual response in bone turnover markers to lasofoxifene therapy. Bone 45: 1044-1052. [crossref]

14. Lindsay R, Hart DM, Aitken JM, MacDonald EB, Anderson JB, et al. (1976) Long-term prevention of postmenopausal osteoporosis by oestrogen. Evidence for an increased bone mass after delayed onset of oestrogen treatment. Lancet 1: 1038-1041. [crossref]

15. Christiansen C, Christensen MS, McNair P, Hagen C, Stocklund KE, et al. (1980) Prevention of early postmenopausal bone loss: controlled 2-year study in 315 normal females. Eur J Clin Invest 10: 273-279. [crossref]

16. Evio S, Tiitinen A, Laitinen K, Ylikorkala O, Valimaki MJ (2004) Effects of alendronate and hormone replacement therapy, alone and in combination, on bone mass and markers of bone turnover in elderly women with osteoporosis. J Clin Endocrinol Metab 89: 626-631. [crossref]

17. Middleton ET, Steel SA (2007) The effects of short-term hormone replacement therapy on long-term bone mineral density. Climacteric 10: 257-263. [crossref]

18. Naessen T, Persson I, Thor L, Mallmin H, Ljunghall S, et al. (1993) Maintained bone density at advanced ages after long term treatment with low dose oestradiol implants. Br J Obstet Gynaecol 100: 454-459. [crossref]

19. Heikkinen J, Vaheri R, Kainulainen P, Timonen U (2000) Long-term continuous combined hormone replacement therapy in the prevention of postmenopausal bone loss: a comparison of high- and low-dose estrogen-progestin regimens. Osteoporos Int 11: 929-937. [crossref]

20. Black DM, Delmas PD, Eastell R, Reid IR, Boonen S, et al. (2007) Once-yearly zoledronic acid for treatment of postmenopausal osteoporosis. N Engl J Med 356: 1809-1822. [crossref]

21. Cummings SR, San MJ, McClung MR, Siris ES, Eastell R, et al. (2009) Denosumab for prevention of fractures in postmenopausal women with osteoporosis. N Engl J Med 361: 756-765. [crossref]

22. Bagger YZ, Tanko LB, Alexandersen P, Hansen HB, Mollgaard A, et al. (2004) Two to three years of hormone replacement treatment in healthy women have long-term preventive effects on bone mass and osteoporotic fractures: the PERF study. Bone 34: 728-735. [crossref]

23. Watts NB, Cauley JA, Jackson RD, LaCroix AZ, Lewis CE, et al. (2017) No Increase in Fractures After Stopping Hormone Therapy: Results From the Women's Health Initiative. J Clin Endocrinol Metab 102: 302-308. [crossref]

24. Delmas PD, Bjarnason NH, Mitlak BH, Ravoux AC, Shah AS, et al. (1997) Effects of raloxifene on bone mineral density, serum cholesterol concentrations, and uterine endometrium in postmenopausal women. $N$ Engl J Med 337: 1641-1647. [crossref]

25. Johnston CC, Bjarnason NH, Cohen FJ, Shah A, Lindsay R, et al. (2000) Long-term effects of raloxifene on bone mineral density, bone turnover, and serum lipid levels in early postmenopausal women: three-year data from 2 double-blind, randomized, placebo-controlled trials. Arch Intern Med 160: 3444-3450. [crossref]

26. Lufkin EG, Whitaker MD, Nickelsen T, Argueta R, Caplan RH, et al. (1998) Treatment of established postmenopausal osteoporosis with raloxifene: a randomized trial. $J$ Bone Miner Res 13: 1747-1754. [crossref]

27. Silverman SL, Christiansen C, Genant HK, Vukicevic S, Zanchetta JR, et al. (2008) Efficacy of bazedoxifene in reducing new vertebral fracture risk in postmenopausal women with osteoporosis: results from a 3-year, randomized, placebo-, and activecontrolled clinical trial. J Bone Miner Res 23: 1923-1934. [crossref]

28. Langer RD, Simon JA, Pines A, Lobo RA, Hodis HN, et al. (2017) Menopausal hormone therapy for primary prevention: why the USPSTF is wrong. Climacteric 20: 402-413. [crossref]

29. Manson JE, Aragaki AK, Rossouw JE, Anderson GL, Prentice RL, et al. (2017) Menopausal Hormone Therapy and Long-term All-Cause and Cause-Specific Mortality: The Women's Health Initiative Randomized Trials. JAMA 318: 927-938. [crossref]

30. Manson JE, Allison MA, Rossouw JE, Carr JJ, Langer RD, et al. (2007) Estrogen therapy and coronary-artery calcification. $N$ Engl J Med 356: 2591-2602. [crossref]

31. Schierbeck LL, Rejnmark L, Tofteng CL, Stilgren L, Eiken P, et al. (2012) Effect of hormone replacement therapy on cardiovascular events in recently postmenopausal women: randomised trial. BMJ 345: e6409.

32. Olie V, Canonico M, Scarabin PY (2011) Postmenopausal hormone therapy and venous thromboembolism. Thromb Res 127: S26-29. [crossref] 
Erik Fink Eriksen (2021) The Role of Menopausal Hormone Therapy and Serms in the Long-Term Treatment of Osteoporosis

33. Tremollieres F, Brincat M, Erel CT, Gambacciani M, Lambrinoudaki I, et al. (2011) EMAS position statement: Managing menopausal women with a personal or family history of VTE. Maturitas 69: 195-198. [crossref]

34. Cummings SR, Ensrud K, Delmas PD, LaCroix AZ, Vukicevic S, et al. (2010) Lasofoxifene in postmenopausal women with osteoporosis. N Engl J Med 362: 686696. [crossref]

35. Cummings SR, McClung M, Reginster JY, Cox D, Mitlak B, et al. (2010) Arzoxifene for prevention of fractures and invasive breast cancer in postmenopausal women. J.Bone Miner
36. Siris ES, Harris ST, Eastell R, Zanchetta JR, Goemaere S, et al. (2005) Skeletal effects of raloxifene after 8 years: results from the continuing outcomes relevant to Evista (CORE) study. J Bone Miner Res 20: 1514-1524. [crossref]

37. Barrett-Connor E, Mosca L, Collins P, Geiger MJ, Grady D, et al. (2006) Raloxifene Use for The Heart Trial, I. Effects of raloxifene on cardiovascular events and breast cancer in postmenopausal women. N Engl J Med 355: 125-137. [crossref]

\section{Citation:}

Erik Fink Eriksen (2021) The Role of Menopausal Hormone Therapy and Serms in the Long-Term Treatment of Osteoporosis. Integr Gyn Obstet J Volume 4(1): 1-5. 